\title{
A DEMOCRACIA DELIBERATIVA: A INSTITUCIONALIZAÇÃO DISCURSIVA DA UNIDADE DA RAZÃO NA MULTIPLICIDADE DAS SUAS VOZES
}

\author{
THE DELIBERATIVE DEMOCRACY: THE \\ DISCURSIVE INSTITUTIONALIZATION OF THE UNITY \\ OF REASON IN THE MULTIPLICITY OF ITS VOICES
}

Karl Heinz Efken*

RESUMO - O presente artigo tem como objetivo principal refletir sobre a leitura discursiva da democracia e do Estado democrático de direito, assim como foi concebida pelo filósofo alemão, Jürgen Habermas, e utilizá-la para um confronto com algumas teorias sociológicas da democracia. Habermas procura identificar, nestes modelos, elementos que colocam em risco aquilo que ele entende por processos deliberativos de formação da opinião e da vontade dos cidadãos, dando ênfase ao seu modelo de uma democracia deliberativa.

PALAVRAS-CHAVE - Teoria do discurso. Democracia deliberativa. Teorias sociológicas.

ABSTRACT - This article aims principally at a reflection on the discursive reading of democracy and the democratic state of law as conceived by the German philosopher Jürgen Habermas, with a view to confront them with some sociological theories concerning democracy. In these models, Habermas seeks to identify elements that put under risk all that he understands as deliberative processes opinion formation and as the citizens will, emphasizing his model of a deliberative democracy.

KEYWORDS - Discourse Theory. Deliberative Democracy. Sociological theories.

* Doutor em Filosofia pela PUCRS e Professor Adjunto III da UNICAP. E-mail: < khefken@ hotmail.com $>$.

\begin{tabular}{l|l|l|l|l|l|} 
Veritas & Porto Alegre & v. 56 & n. 3 & set./dez. 2011 & p. 125-144
\end{tabular}




\section{Introdução}

Jürgen Habermas pode ser considerado o defensor incansável da ideia da "unidade da razão na multiplicidade das suas vozes", na República Federal da Alemanha, pós-guerra. Ele integra a geração de pensadores marcados pela memória e pela vivência dos horrores da nãorazão e da evaporação dos últimos resquícios da confiança numa razão essencialista ${ }^{1}$, nos campos de batalha das duas Grandes Guerras e na efetivação histórica da razão instrumental por meio da sua elevação à razão última do Estado. ${ }^{2}$

A memória viva desses momentos cruciais na história da Alemanha torna compreensível a sua opção por uma democracia deliberativa ${ }^{3} \mathrm{e}$ pelo Estado democrático de direito. Diante das ameaças às instituições existentes da liberdade, nas democracias estabelecidas, a inquietação reinante possui uma razão mais profunda: "ela deriva do pressentimento de que, numa época de política inteiramente secularizada, não se pode ter nem manter um Estado de direito sem democracia radical". ${ }^{4}$

Procuramos compreender, neste artigo, como Habermas tenta recuperar as forças comunicativas inerentes às instituições das sociedades democráticas contemporâneas e propõe utilizá-las na leitura e compreensão discursiva do Estado democrático de direito.

Reese-Schäfer fala da tentativa habermasiana de

1 Cf. HABERMAS, Jürgen. Direito e democracia: entre facticidade e validade. Trad. de Flávio B. Siebeneichler. Rio de Janeiro: Tempo Brasileiro, 1997. v. 1. p. 12. (doravante DD1)

2 Habermas, referindo-se ao século XX, constata: "Os fenômenos de violência e barbárie determinam a assinatura dessa era. Desde Horkheimer e Adorno até Baudrillard, de Heidegger a Foucault e Derrida, os traços totalitários da era ficaram gravados na estrutura mesma dos diagnósticos do período". Apesar disso, Habermas interroga: "Isso me permite perguntar se essas interpretações negativistas, que se deixam aprisionar pelo terror das imagens, eventualmente não deixam escapar o outro lado dessas catástrofes" (HABERMAS, Jürgen. A constelação pós-nacional: ensaios políticos. Trad. Marcio Seligmann-Silva. São Paulo: Littera Mundo, 2001, p. 60 e ss).

3 "O terceiro modelo de democracia que me permito sugerir baseia-se nas condições de comunicação sob as quais o processo de político supõe-se capaz de alcançar resultados racionais, justamente por cumprir-se, em todo seu alcance, de modo deliberativo" (grifo nosso). HABERMAS, Jürgen. A inclusão do outro: estudos de teoria política. Trad. George Sperber e Paulo Astor Soethe. São Paulo: Loyola, 2002, p. 277). Habermas fala da compreensão genuinamente procedimentalista da democracia: "A chave desta concepção consiste precisamente no fato de que o processo democrático institucionaliza discursos e negociações com o auxílio de formas de comunicação as quais devem fundamentar a suposição da racionalidade para todos os resultados obtidos conforme o processo"(HABERMAS, Jürgen. Direito e democracia: entre facticidade e validade. Trad. Beno Siebeneichler. Rio de Janeiro: Tempo Brasileiro, 1997. p. 27. (doravante DD2)

4 DD1, p. 13. 
[...] mediar uma teoria sociológica do direito, que parte dos fatos do sistema dos direitos, com uma teoria filosófica da justiça. A mediação consiste numa teoria política da democracia deliberativa e da sociedade civil, pois não são as instituições rígidas constitucionalmente mapeadas do Estado, mas a soberania da deliberação pública que pode prover uma abertura suficiente. A teoria normativa da justiça corre o risco de não discernir suficientemente os fatos graves da realidade política, a teoria sociológica está sob suspeita de positivismo. A atração do projeto de Habermas consiste em superar, através de uma teoria integrativa e interdisciplinar, essa dupla redução. ${ }^{5}$

Habermas não se cansa de defender argumentativamente e no espaço público o processo de reconstrução reflexiva de uma comunidade de sujeitos atuantes e falantes discursivamente ${ }^{6}$, de cidadãos livres e autônomos, parceiros de direito e participantes dos processos de formação política da opinião e da vontade, para garantir o fluxo das liberdades comunicativas na configuração das múltiplas forças que atuam na complexidade das sociedades modernas. Elas exercem o papel de dinamização e renovação permanentes dos poderes estabelecidos, por meio da articulação das forças anárquicas oriundas da esfera pública.

Recorremos ao próprio Habermas para apontar o objetivo da presente reflexão: "Eu gostaria de mostrar que o derrotismo normativo, no qual os vários matizes da sociologia política desembocam, não é fruto de evidências concretas, mas do uso de estratégias conceituais falsas". ${ }^{7}$

\section{O fenômeno da dissolução do conteúdo idealista das teorias normativas de democracia}

Para a obtenção de certa simetria entre as forças atuantes na sociedade, como um todo, e no Estado de direito, como a sua expressão jurídico-política discursivamente produzida e elevada ao nível de uma objetividade de natureza intersubjetiva, é necessário saber como se comporta o fluxo do poder regulado por normas e o fluxo não-oficial do poder não-legitimado no circuito do poder regulado pelo Estado de direito. Torna-se preocupante aquilo que diz respeito à forma sofisticada,

5 REESE-SCHÄFER, Walter. Compreender Habermas. Trad. Vilmar Schneider. Petrópolis: Vozes, 2008, p. 84.

6 Cf. HABERMAS, Jürgen. A inclusão do outro: estudos de teoria política. Trad. George Sperber e Paulo Astor Soethe. São Paulo: Loyola, 2002: “(...) a razão prática (...) restringese a regras discursivas e formas argumentativas que extraem seu teor normativo da base validativa da ação que se orienta ao estabelecimento de um acordo mútuo, isto é, da estrutura da comunicação linguística" (p. 278).

7 DD2, p. 58. 
porém sistemática, de "terapia do emagrecimento normativo" ${ }^{8}$ dos modelos normativos de democracia moderna.

Os últimos anos, assim argumenta Habermas, têm mostrado que o conteúdo idealista das teorias normativas se dissolve, quando são confrontadas com uma realidade na qual o "poder 'ilegítimo' irrompe no fluxo do poder regulado pelo Estado de direito". ${ }^{9} \mathrm{O}$ enfraquecimento da esfera pública política e do complexo parlamentar facilita a invasão do processo de legislação pelo poder social de interesses organizados, comprometendo a sua legitimidade. O poder administrativo tornase autônomo e pressionado pelos sistemas funcionais das grandes organizações, liga-se a um poder social eficaz, "(...) formando uma contracorrente que atravessa o fluxo dos processos de decisão democráticos, dirigidos pelo poder comunicativo". ${ }^{10}$

Interessa notar que aqueles que descrevem esses movimentos operam com conceitos de poder empiristas (o que determina de antemão a percepção do objeto em questão), tornando obsoletos os resultados obtidos pelo trabalho reconstrutivo. Poderíamos dizer o seguinte: a constatação da dissolução do conteúdo idealista das teorias normativas de democracia leva os empiristas à elaboração de conceitos de poder que apenas refletem esse fenômeno, mas, à medida que os absolutizam e utilizam para a interpretação e explicação de todos os processos políticos envolvidos na estruturação e constituição das sociedades modernas, cometem a falácia da generalização - o que vale apenas para um particular se atribui ao todo. ${ }^{11}$

Habermas, a fim de compreender melhor as contradições inerentes às propostas empiristas, lança um olhar crítico sobre algumas teorias sociológicas de democracia que se esforçam em solucionar o problema:

\footnotetext{
DD2, p. 62.

DD2, p. 62.

DD2, p. 58.
}

11 Com a crítica às teorias empiristas da democracia, Habermas não pretende fugir de um confronto com o fenômeno da dissolução do conteúdo idealista das teorias normativas da democracia. Não se trata de negar um processo histórico, mas de encontrar uma teoria explicativa do fenômeno em questão e propor possíveis soluções para o problema do desgaste normativo que assola as democracias contemporâneas. Referindo-se à comunidade comunicacional ideal, como modelo de socialização comunicativa "pura", Habermas faz a seguinte alerta: "No entanto, esse simples modelo conceitual não deve ser interpretado erroneamente. Ele refere-se a sociedades concretas, localizadas no espaço e no tempo, e já diferenciadas. Por isso, ele não distingue entre processos de entendimento discursivo e fundamentos do agir comunicativo, uma vez que conta com os contextos do mundo da vida. (...) A partir do momento em que entendemos a socialização (...) mediada através da comunicação, não contamos mais com seres inteligíveis, oniscientes, sem corpo e que agem fora de um contexto; porém com atores ligados a um corpo, socializados em formas de vida concretas, localizados no tempo histórico e no espaço social (...)" (DD2, p. 51-53). 
não visam apenas compreender o poder político no contexto de articulação dos outros poderes que participam do jogo de luta por influência, mas também de procurar domesticá-lo em termos democráticos.

Para o nosso autor, existem fontes normativas que escapam ao olhar empirista e descritivo das sociedades modernas. Há forças sociais e históricas que não se deixam enquadrar nas categorias pré-elaboradas e impõem ao teórico o árduo trabalho de criar conceitos e teorias novas e sempre mais apuradas em termos de compreensão dos processos históricos de formação da pessoa humana e da sua vida em comunidade.

\section{A democracia na perspectiva das teorias sociológicas}

A teoria do pluralismo parte da compreensão instrumentalista da política. O poder político e administrativo expressam formas diferentes do poder social, o que significa o poder social determinar a força de imposição de interesses organizados. O modelo "[...] introduz um processo circular, que liga o poder social dos clientes aos partidos que conseguem o poder político, o processo de legitimação às operações e realizações do Estado e, por último, fechando o círculo, liga esse processo de implementação às pretensões dos clientes". ${ }^{12}$ Para o funcionamento adequado dos fluxos do poder político, isto é, fluxo correspondente às forças sociais existentes, supõe o modelo uma distribuição mais ou menos igual do poder social.

A teoria social do pluralismo coloca no lugar dos cidadãos e dos seus interesses individuais organizações e interesses organizados e, como parte da ideia de uma democracia de concorrência entre esses interesses diferentes, supõe a possibilidade de "[...] um equilíbrio social do poder, no nível de distribuição do poder político, de tal modo que a política estatal leve em consideração um amplo leque de interesses simétricos" ${ }^{13} \mathrm{~A}$ fragilidade dessa proposta salta aos olhos e levou a elaboração de "[...] uma teoria da elite, expurgada dos acréscimos pluralistas, e que reduz essencialmente o papel do processo democrático à escolha plebiscitária entre dirigentes, portanto a uma seleção de condutores". ${ }^{14}$ Mas, o que e quem garante que as elites condutoras satisfazem os interesses dos que não fazem parte da elite?

Diante de massas de eleitores passíveis, que perderam as suas expectativas normativas quanto ao processo democrático, fica a esperança na racionalidade das elites que decidem e desejam inovações, garantindo

12 DD2, p. 59.

13 DD2, p. 60.

14 DD2, p. 60. 
as funções sociais do Estado. O sistema de administração assume poderes extraordinários e decide as funções e fins políticos. Segundo Habermas,

[...] uma visão normativa coloca o problema das condições nas quais o Estado, uma vez que não é dirigido pelos interesses sociais, pode ao menos desenvolver uma sensibilidade em relação a esses interesses. $O$ sistema político tem que assumir a articulação das necessidades públicas relevantes, dos conflitos latentes, dos problemas recalcados, dos interesses que não se deixam organizar, etc. (grifo nosso). ${ }^{15}$

A separação artificial dos diversos poderes, que compõem o sistema sociopolítico, provoca a frustração das expectativas normativas dos que compõem a comunidade político-jurídica ou nega a eles qualquer participação na construção ou reconstrução dessas mesmas expectativas. Quando as expectativas normativas da elite se confundem com os seus interesses próprios ou com os interesses das massas interpretados por ela, em função de um projeto sociopolítico e econômico maior, estamos sempre diante de uma profunda distorção daquilo que aprendemos da história em termos de governo democrático baseado na soberania popular e expressado, em sua forma jurídico-política, na ideia do Estado de direito.

Desde os anos 60, assim constata Habermas, temo-nos confrontado com um sistema administrativo a agir mais no "nível reativo" e com um "Estado ativo" que encontra os seus limites no poder de sistemas funcionais e das grandes organizações. ${ }^{16}$ Por outro lado, cresceu a imprevisibilidade dos eleitores supostamente esclarecidos e aumentaram os mecanismos de manipulação dos mesmos. Instalou-se uma crise de legitimação nos centros do poder: a elite carece de força representativa e as massas se entregam a uma espécie de quietismo paralisante.

Habermas identifica, nesse ponto de desenvolvimento, uma bifurcação da teoria do pluralismo.

15 DD2, p. 61. A teoria das elites sucumbe a uma tentação antiga e fatal, para qualquer sistema político de conteúdo normativo democrático, de transferir a responsabilidade pela condução da "res publica" para um grupo seleto de "iluminados" ou, pelo menos, instruídos de forma privilegiada, capaz de identificar, interpretar e traduzir os supostos interesses dos menos favorecidos quanto a uma sensibilidade superior em relação à compreensão dos "desígnios" da história humana em sociedade.

16 A política econômica dos assim chamados países em vias de desenvolvimento funciona segundo tal ação reativa. As decisões são tomadas nos centros de poder dos países industrializados e desenvolvidos (pelo menos economicamente); os que dependem dessas decisões e não participaram dos procedimentos de tomada de decisões e, apesar disso, sofrem as consequências das mesmas, reagem conjunturalmente, sem um projeto maior e sem perspectivas de mudanças em termos de distribuição de poder de decisão. A assimetria crônica é a constante nessas relações. 
De um lado, a teoria do sistema elimina os derradeiros laços do modelo normativo que servira de ponto de partida, limitando-se essencialmente aos problemas de regulação de um sistema político declarado autônomo e reassumindo os problemas da velha teoria do Estado; de outro lado, a teoria econômica da democracia dedica-se quase que exclusivamente ao processo de legitimação, apoiando-se nos pressupostos de um individualismo metodológico. ${ }^{17}$

Os dois princípios provocam uma "terapia de emagrecimento normativo" 18 , pois a racionalidade autorreflexiva da regulação e a racionalidade decisionista expressa no voto representam um reducionismo normativo em relação às expectativas normativas inerentes a uma teoria da democracia, que visa a explicar e interpretar os interesses e necessidades de uma comunidade de cidadãos ${ }^{19}$ que se entende como portadora do poder político, reguladora dos seus intercâmbios comunicacionais, jurídicos, administrativos e culturais.

Em todo caso, para Habermas, há evidências empíricas que desautorizam os modelos a partir de uma base de decisão egocêntrica. A visão egocêntrica democrática se nega a si mesma, pois se fecha em si mesma, uma vez que não explica o salto qualitativo do "ego" ao "alter"; não atinge, em outras palavras, o "outro generalizado", condição da possibilidade da formação de uma comunidade de cidadãos que se reconhecem na reciprocidade de direitos e deveres atribuídos a partir da sua autocompreensão como sujeitos autônomos e livres. Uma sociedade de indivíduos atomizados não produz, sem mediações, sistemas sociopolíticos com estrutura interna intersubjetiva e fronteiras porosas abertas ao intercâmbio intersistêmico ou relações intercomunicacionais com expectativas normativas recíprocas que exigem respostas em termos de "sim" ou "não" quanto às suas pretensões de validade.

Quanto à teoria dos sistemas ${ }^{20}$, ela elimina, quase por completo, o potencial comunicativo de indivíduos ou de coletividades, porque aposta numa sociedade constituída por uma rede de sistemas parciais autônomos, que não se comunicam entre si e insistem em semânticas próprias, o que cria fronteiras fechadas umas em relação às outras. $\mathrm{O}$

17 DD2, p. 61.

18 DD2, p. 62

19 Como tal, a teoria da democracia se revela ser a expressão e, ao mesmo tempo, a interpretação e explicação dos anseios e das necessidades daqueles que compõem a sociedade. Trata-se de uma teoria que nasce de uma prática intersubjetiva de vivências partilhadas, se torna reflexiva em relação a essa prática, a fim de torná-la crítica.

20 Cf. DD2, p. 221 ss; HABERMAS, Jürgen. Direito e moral. Lisboa: Instituto Piaget, 1999, p. 69 ss. Habermas se propõe a fazer uma análise de algumas das características essenciais da teoria funcionalista do direito de Luhmann e aponta para fenômenos, nos quais, esta estratégia de explicação se cansa em vão. 
sistema político se torna um entre outros. "A teoria do sistema atribui a formação política da opinião e da vontade, dominada pela concorrência entre os partidos, a um público de cidadãos e de clientes incorporados ao sistema político, porém desligados das raízes que os prendem ao mundo da vida, isto é, a sociedade civil, a cultura política e a socialização". ${ }^{21}$

Esse desligamento do mundo da vida ${ }^{22}$ empobrece o processo de formação da opinião e da vontade, enfraquece suas forças comunicacionais livres e impede a sua institucionalização jurídica, uma vez que separa os subsistemas político e jurídico. Aumenta o fluxo informal em detrimento da sensibilidade pela responsabilidade política. A força explicativa das teorias sistêmicas em relação à diminuição da normatividade do modelo normativo de democracia não compensa a sua incapacidade de propor uma nova teoria de democracia. A incapacidade de se comunicarem entre si leva a um autismo dos sistemas e, para Habermas, “[...] atinge especialmente o sistema político, o qual se fecha autorreferencialmente em relação a seus ambientes circundantes. E este encapsulamento autopoético o impede quase por completo de integrar a sociedade em seu todo [... "23, objetivo que se propõe. ${ }^{24}$

Ambos os sistemas desconsideram o nexo constitutivo existente entre direito e poder político. A separação gera um tipo de incomunicacionalidade que mina o próprio processo de constituição do Estado democrático de direito, pois impossibilita o agir comunicativo que, pela própria natureza, procura um entendimento entre as diversas partes do todo, efetivando as forças ilocucionárias de ligação, as quais "desestabelizam" fronteiras

${ }^{21}$ DD2, p. 62 (grifo nosso).

22 O conceito de mundo da vida constitui "(...) o pano de fundo das práticas comunicativas, de condição de possibilidade de qualquer forma de entendimento, enquanto conjunto de sentidos predeterminados, a partir do qual os indivíduos socializados se abastecem para compreender, interpretar e agir sobre os mundos. (...) É ele que permite aos sujeitos sociais se entenderem mutuamente, sobre algo nos mundos, seja o natural, o social ou o subjetivo" (ARAGÃO, Lúcia. Habermas: filósofo e sociólogo do nosso tempo. Rio de Janeiro: Tempo Brasileiro, 2002, p. 117-118). "Os componentes do mundo da vida - a cultura, a sociedade e as estruturas da personalidade - formam conjuntos de sentido complexos e comunicantes, embora estejam incorporados em substratos diferentes" (HABERMAS, Jürgen. Pensamento Pós-metafísico: estudos filosóficos. Rio de Janeiro: Tempo Brasileiro, 1990, p. 98). Veja, ainda, sobre o conceito de mundo da vida: OLIVEIRA, Nythamar Fernandes de. Tractatus ethico-politicus: genealogia do ethos moderno. Porto Alegre: Edipucrs, 1999. Cap. VIII. Quanto aos conceitos de mundo da vida e sistema, veja: HABERMAS, Jürgen. Legitimationsprobleme im Spätkapitalismus. Frankfurt am Main: Suhrkamp, 1996.

23 DD2, p. 65.

24 A proposta de uma democracia deliberativa é justamente a superação do "encapsulamento autopoético": "Pois o âmago da política deliberativa consiste precisamente numa rede de discursos e de negociações, a qual deve possibilitar a solução racional de questões pragmáticas, morais e éticas - que são precisamente os problemas acumulados de uma fracassada integração funcional, moral e ética da sociedade" (DD2, p. 47). 
estabelecidas de forma artificial e atuam de modo "anárquico" no meio dos discursos juridicamente institucionalizados.

\section{A reabilitação do conceito de política deliberativa processada por Jon Elster}

A fim de evidenciar melhor as deficiências da teoria econômica da democracia e da teoria dos sistemas, Habermas recorre a Elster, que procura detectar as dificuldades que aparecem quando se aplica a teoria da escolha racional aos processos políticos.

Elster corrige tais distorções e " [...] descreve o processo democrático como um mecanismo que modifica preferências através de discussões públicas" 25 , o que significa contar com comportamentos ético-sociais e razões morais. Interessando-se pelos aspectos procedimentais da formação racional da vontade, ele acrescenta ao agir estratégico um agir regulado por normas. Para Elster, “[...] ninguém conseguiria utilizar estrategicamente normas num caso concreto, se ele não pudesse supor em geral o reconhecimento intersubjetivo de normas. [...] a validade social de normas antecede o ganho propiciado por uma orientação que simula seguir tais normas". ${ }^{26}$ Quer dizer, quem pretende agir estrategicamente tem que partir da existência, mesmo sendo mínima, de um agir comunicativo (segundo regras já estabelecidas) e, consequentemente, de sujeitos capazes de ação e fala e dispostos a ouvir e a avaliar o ato de fala de um outro falante (pretensões de validade). Se não fosse assim, aquele que age estrategicamente não teria ninguém a ser manipulado; restar-lhe-ia apenas o monólogo ou a luta entre iguais.

Uma comunidade que assumisse o agir estratégico como a única forma de relacionamento entre os seus membros seria fadada à autodestruição ou entraria num processo lento de concentração do poder nas mãos de uma "elite de estrategistas políticos" e, por consequência, terminaria numa ditadura política. O problema de tudo isso consiste na crença errônea na possibilidade de alguém poder decidir-se racionalmente por um comportamento irracional. ${ }^{27}$

25 DD2, p. 66-67.

26 DD2, p. 67.

27 Um fenômeno dessa ordem pode ser observado no capitalismo contemporâneo, o qual despolitiza, por um lado, o mercado, que é gerado e movimentado por uma razão instrumental simples, a obtenção de lucro a qualquer preço; por outro, politiza as decisões no espaço econômico, tentando utilizá-lo como meio de integração. Essas forças conflitantes de desintegração-integração só serão, em parte, conciliadas, quando os processos de decisão, ligados ao poder econômico (dinheiro) e administrativo (burocracia), passam a ser reintegrados nos processos políticos que ultrapassam os interesses particulares e visam a um bem comum. 
Habermas critica, na proposta de Elster, a permanência de premissas empiristas, segundo as quais o agir conforme normas se diferencia do agir estratégico apenas pela ausência de uma orientação em função dos efeitos da ação.

Enquanto Elster insiste na exclusão mútua de normatividade e racionalidade, as coordenações motivadas de modo racional continuam na forma de combinações entre atores que agem estrategicamente. Mesmo assim, um acordo racional como negociação de compromissos exige tanto argumentação racional quanto ameaças e promessas. A presença da argumentação racional na negociação de compromissos introduz critérios de validade, que devem ser respeitados por todos os partidos envolvidos, caso queiram alcançar um consenso (mesmo mínimo). A necessidade da argumentação e de argumentos idênticos (para garantir um entendimento), implica, apesar da finalidade estratégica da ação, um julgamento imparcial de interesses e conflitos, o que, por sua vez, caracteriza a presença de um discurso prático. Daí resulta, segundo Habermas, a necessidade de comunicação entre participantes da argumentação que procuram um entendimento, ao lado de atores que continuam influenciar-se estrategicamente: "Elster tem que alargar o conceito de racionalidade e aceitar a idéia de que as normas e orientações valorativas possuem um núcleo racional". 28

A introdução do conceito de justiça por Elster possibilita, agora, atribuir à política a tarefa de criar e garantir condições de vida no interesse simétrico de todos. Com isso se afasta ainda mais da compreensão empirista do poder: "[a] formação parlamentar da opinião e da vontade não pode ser explicada segundo as premissas empiristas de um equilíbrio de interesses, regulado pelo poder" 29 , a reconstrução racional de padrões de argumentação possibilita um entrelaçamento entre o entendimento apoiado na validade e o influenciamento orientado pelo sucesso.

Os debates de hoje são influenciados por pressupostos da política deliberativa: "Os pressupostos comunicacionais que permitem regular deliberativamente as contendas estão institucionalizados eficazmente em corporações parlamentares, permitindo que o procedimento democrático filtre argumentos e deixe vir à tona os que são capazes de produzir legitimidade". ${ }^{30}$ Aqui é interessante notar que a esfera

28 DD2, p. 69.

29 DD2, p. 70.

30 DD2, p. 71 (grifo nosso). 
pública ${ }^{31}$ das comunicações políticas exerce uma coerção procedimental saudável. A publicidade de debates e de procedimentos deliberativos representa o melhor antídoto às negociatas feitas a portas trancadas.

Com isso, fica claro que as condições para a formação política racional da vontade devem ser detectadas também no nível social dos procedimentos institucionalizados de formação de opinião e de deliberação, o que nos coloca diante de uma teoria do discurso e não se trabalha mais com a teoria da escolha racional. ${ }^{32}$

As formas de comunicação e os processos institucionalizados de formação de opinião e procedimentos de deliberação acima mencionados carregam em si a própria razão prática. Esta, portanto, atua para além da sua presença já garantida nas cabeças de atores coletivos ou singulares, dilui-se e assume uma forma mais "democrática", desfazendo-se, em parte, de seu peso metafísico, o que a torna parte integrante e integradora dos processos de formação política.

A eficácia da razão procedimentalizada se mede, agora, pelo nível discursivo das comunicações políticas. Atores coletivos e singulares que dispõem de um poder sustentado e imposto pela ameaça e pelo poder administrativo de funcionários são contrabalançados pelo poder produzido comunicativamente, poder resultante de procedimentos políticos deliberativos.

\section{H. Willke: a problemática da integração de uma sociedade decomposta em sistemas funcionais auto poeticamente autônomos}

Wilke procura responder ao grave problema da integração da sociedade como um todo. Como garantir essa integração numa sociedade que se

31 "A esfera pública não pode ser entendida como uma instituição, nem como uma organização, pois, ela não constitui uma estrutura normativa capaz de diferenciar entre competências e papéis, nem regula o modo de pertença a uma organização, etc. (...) A esfera pública pode ser descrita como uma rede adequada para a comunicação de conteúdos, tomadas de posição e opiniões; nela os fluxos comunicacionais são filtrados e sintetizados, a ponto de se condensarem em opiniões públicas enfeixadas em temas específicos. (...) A esfera pública constitui principalmente uma estrutura comunicacional do agir orientado para o entendimento, a qual tem a ver com o espaço social gerado no agir comunicativo, não com as funções nem com os conteúdos da comunicação cotidiana" (HABERMAS, Jürgen. Pensamento Pós-metafísico: estudos filosóficos. Rio de Janeiro: Tempo Brasileiro, 1990, p. 92).

32 Ver, a respeito da teoria da escolha racional, KOLLER, Peter. Rationales Entscheiden und moralisches Handeln. In: NIDA-RÜMELIN, Julian. (Hrsg.), WESSELS, Ulla. Praktische Rationalität: Grundlagenprobleme und ethische Anwendung des rational choiceParadigmas. Berlin, New York: de Gryter, 1993. Cap. IX, p. 281-311. (Perspektiven der analytischen Philosophie, Bd. 2). 
pretende um conjunto organizado de sistemas funcionais fechados em si? Segundo a visão da teoria dos sistemas:

[...] o sistema político pode prescindir das fontes autônomas do direito legítimo, após a positivação deste último. Isso significa que a política, seguindo o caminho de outros sistemas funcionais, tornou-se independente, transformando-se num círculo de comunicação fechado em si mesmo. Ligando-se ao sistema do direito, responsável pela garantia da legalidade, tal política contingente, apoiada apenas na autorreferência, extrai de si mesma tudo o que necessita em termos de legitimação. Pois a necessidade de legitimação pode ser coberta de modo paternalista, tanto nas estruturas de maior densidade organizacional, como nas linhas que ligam o governo e a aposição, na concorrência entre os partidos, e até na rede subcomplexa do público de eleitores. ${ }^{33}$

Habermas assume como tarefa submeter a teoria do Estado de Wilke a uma crítica imanente. Para Wilke, há um espaço entre Estado e sociedade preenchido por sistemas de negociação que atribuem à política a função de supervisor terapêutico para garantir a unidade social global em meio a uma sociedade descentrada, que não mais encontra no Estado seu momento de representação. Apesar disso, vê no Estado a garantia de uma integração de estancamentos sociais.

O autor aceita a teoria dos sistemas, mas procura suavizá-la pela introdução de vias comunicacionais entre os subsistemas funcionais, recorrendo a uma linguagem que, apesar das semânticas próprias dos sistemas, possibilitaria uma comunicação entre eles. Tal integração torna-se necessária, "pois, se a sociedade descentrada não pudesse mais manter a sua unidade, também não poderia mais aproveitar-se do aumento de complexidade de suas partes e cairia vítima de seus ganhos em termos de diferenciação". ${ }^{34}$ Para Wilke, não há mais primado de uma das partes nem validação do sistema global a partir da validade daquilo que é universal, mas a racionalidade do sistema vem da harmonização reflexiva do particular.

Habermas sintetiza em três pontos a descrição dessa sociedade, que é integrada e, ao mesmo tempo, tutelada por um equilíbrio intersistêmico:

a) através de sistemas de negociação não hierarquizados, o Estado supervisor procura afinar-se com sistemas sociais funcionais da sociedade (...);

b) a política reguladora do sistema tem que continuar servindo-se da linguagem do direito, em especial do direito reflexivo, porém não necessita mais de seus programas condicionais ou teleológicos;

33 DD2, p. 73.

${ }^{34}$ DD2, p. 74. 
c) ao passar do plano da formação democrática da opinião e da vontade das pessoas para o das relações intersistêmicas, a integração deve manter intacta o 'conteúdo essencial' da democracia. ${ }^{35}$

Apesar da força explicativa dessa proposta em relação ao problema da integração da sociedade, Habermas a submete a uma crítica construtiva, a fim de evidenciar, mais uma vez, o problema da legitimação inerente às teorias dos sistemas. O primeiro problema tem a ver com a dificuldade de explicar como perspectivas egocêntricas de indivíduos que agem no interesse próprio podem ser reunidas de tal forma, que haja inclusão dos interesses dos outros. A teoria dos sistemas, assim argumenta Habermas, "[...] é incapaz de explicar como sistemas autopoeticamente fechados conseguem romper o círculo da regulação autorreferencial da autopoiesis e da autorreferência". ${ }^{36}$

Willke pretende superar a barreira das gramáticas próprias de cada sistema por um novo tipo de regras que transcendem os mundos fechados dos diferentes subsistemas e atuam, assim poderíamos dizer, nas interfaces. Daí deve emergir do tatear conjunto de sistemas semanticamente fechados, regulados pela observação, uma linguagem que simula exatamente aquilo que a linguagem comum, origem das semânticas especializadas, realiza normalmente. ${ }^{37}$ Tal proposta não convence Habermas, uma vez que os sistemas não compartilham um mundo comum e carecem de compatibilidade entre jogos de linguagem.

Outro ponto crítico se refere à compreensão do Estado supervisor - definido por Willke como defensor da racionalidade do todo contra a ameaça da absolutização da racionalidade dos sistemas parciais. Para isso, é necessário continuar defendendo a ideia do Estado do direito, justamente para evitar que sistemas de negociação, com a sua própria dinâmica, minem a legitimidade dos processos democráticos do fluxo do poder:

Sociedades altamente complexas podem ser tidas como democráticas quando essa ideia (do Estado de direito) é estendida à sociedade como um todo e quando a estruturação específica da sociedade permite garantir e promover a autonomia e a diferenciação de seus sistemas. Isso constitui não apenas um fim em si mesmo para a manutenção do grau de diferenciação funcional atingido, mas serve também para a generalização da proteção dos direitos fundamentais dos sujeitos privados. ${ }^{38}$

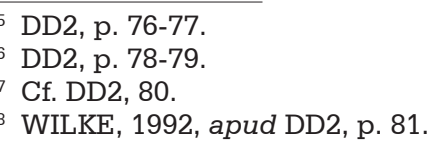


Esse modelo se afasta da realidade que parece ser diferente, pois não há uma harmonia preestabelecida entre o aumento da complexidade dos sistemas funcionais e a realização dos direitos fundamentais das pessoas privadas. As sociedades modernas, reguladas por negociações neocorporativistas, geram grupos de populações empurrados para a periferia e privados de bens coletivos, o que lhe enfraquece a proteção via direitos fundamentais. Quando o direito institucional contribui para a afirmação dos sistemas funcionais como fim em si mesmo, "[...] a 'autonomia e a diferenciação' das pessoas privadas têm que concorrer com as dos sistemas, inclusive no âmbito da circulação 'oficial' do poder, a fim de obter a proteção do direito". ${ }^{39}$

O Estado de direito não pode perder o contato com as pessoas atualmente não envolvidas; ele deve conservar o vínculo com o público dos cidadãos que têm o direito e condições de perceber, identificar e tematizar publicamente a inaceitabilidade de sistemas de funcionamento. Quer dizer, o Estado de direito, apesar de estar atuando no âmbito de sistemas, não pode deixar de lutar pela sobrevivência daqueles que o contestam. Os especialistas se revelam, normalmente, inimigos da formação democrática da opinião e da vontade. A história nos mostra exemplos da cooptação de cientistas e intelectuais (ideólogos) pelo poder político e econômico, contribuindo para o estabelecimento e a continuidade de regimes totalitários e excludentes.

Um último problema se refere à coordenação funcional dos sistemas na perspectiva do reducionismo cognitivo:

o saber relevante para a regulação, produzido por vários grupos de especialistas deve ser transformado em políticas e traduzido em programas jurídicos através de juristas esclarecidos pela teoria do sistema. Essa concepção apoia-se na ideia não realista de que o saber dos especialistas, mobilizado profissionalmente, pode prescindir de valores e de pontos de vista morais. ${ }^{40}$

Há, aqui, uma espécie de contradição, pois, à medida que a coordenação funcional envolve questões políticas, toca em problemas éticos e morais. Apenas o fundo do mundo da vida é capaz de evidenciar as consequências de uma integração insuficiente do sistema. O mundo da vida dispõe de uma sensibilidade para detectar e tematizar interesses feridos e identidades ameaçadas, porque nele a comunicação procura o entendimento (a linguagem ainda está intacta) e o fluxo do poder não sofre, ainda, as influências da razão estratégica e instrumental que atuam quando entramos no âmbito das negociações por interesses alienados, que se afastam, sempre mais, do bem comum.

39 DD2, p. 82.

40 DD2, p. 83. 
Apesar da sua ligação forte com a teoria do sistema, Wilke tem que admitir a necessidade da política deliberativa no fluxo do poder na totalidade do sistema democrático de formação da opinião e da vontade dos cidadãos. Os potenciais da ação comunicativa, mais uma vez, desmentem a possibilidade de substituir os indivíduos singulares por um público pseudodemocrático de especialistas organicamente ligados a um sistema especializado na máxima exploração das suas competências. "[A] integração de uma sociedade altamente complexa", assim argumenta Habermas, "não se efetua através de um sistema paternalista que ignora o poder comunicativo do público de cidadãos". ${ }^{41}$

A integração de uma sociedade complexa passa pelo medium de uma linguagem comum ainda não cooptada nem desvirtuada pelos códigos especializados. Ela possibilita a articulação das redes periféricas da esfera pública política. Para garantir tal articulação, direito e política não podem ser entendidos como sistemas funcionais fechados. O sistema político deve se manter aberto ao mundo da vida, e a ação política encontra nos contextos do mundo da vida seu referencial crítico, para não dizer, sua razão de ser.

É uma visão distorcida aquela que se fixa nos complexos sociais altamente organizados e ocupados, quase exclusivamente, com questões de coordenação funcional. Além dos sistemas de negociação neocorporativistas, deve-se contar com "[...] formas participatórias de envolvimento, que ligam uma administração implementadora aos discursos de seus clientes, levados a sério como cidadãos". 42

As análises e os diagnósticos de Elster e Wilke, apesar da sua inclusão de processos deliberativos e potenciais comunicativos na formação política da vontade e na integração da sociedade, desconsideram o papel de a linguagem comum multifacetada ser capaz de exercer:

Ela é o medium do agir orientado para o entendimento, através do qual o mundo da vida se reproduz e os próprios componentes do mundo da vida se entrelaçam entre si. O modo de operar de sistemas de ação altamente especializados em reprodução cultural (escola), em socialização (a família) ou em integração social (o direito), não se configura em processos completamente distintos e estanques. ${ }^{43}$

O componente social do mundo da vida se constitui da totalidade de relações interpessoais ordenadas legitimamente e de coletividades, associações e organizações especializadas em determinadas funções.

41 DD2, p. 84 (grifo nosso).

42 DD2, p. 85.

43 DD2, p. 79-80. 
Os meios de sua regulação são institucionalizados juridicamente e, assim, nele ancorados. Mais uma vez, a linguagem do direito possibilita a ligação entre mundo da vida e mundo sistêmico. A linguagem comum torna-se comum a todos os componentes da sociedade, ela garante uma orientação para o entendimento de todas as ações, em alguns casos mais, em outros menos, dependendo do nível discursivo dos fluxos comunicacionais diferenciados e interligados que compõe a totalidade comunicativa da sociedade.

\section{Uma proposta aproximativa à questão relativa à implantação da circulação do poder regulado pelo Estado de direito}

Habermas, inspirando-se em Bernhard Peters ${ }^{44}$, procura desenvolver um modelo sociológico orientado para o peso empírico do fluxo oficial do poder prescrito pelo Estado de direito. Este autor, semelhante a Elster e Wilke, tenta compreender a circulação do poder no interior da sociedade, entre os seus diversos componentes, a fim de obter uma resposta à problemática da integração.

Para Peters, "[o]s processos de comunicação e de decisão do sistema político constitucional são ordenados no eixo centro-periferia, estruturados através de um sistema de comportas e caracterizados através de dois tipos de elaboração de problemas". ${ }^{45}$ Há um núcleo do sistema jurídico-político formado pela administração e governo, o judiciário e as instituições parlamentares, isto é, o executivo, o legislativo e o judiciário, além da formação democrática da opinião e da vontade. Esse centro é estruturado em si de forma "poliárquica". Cada complexo institucional apresenta uma capacidade de ação específica segundo a sua densidade de complexidade organizatória. Uma periferia interna e outra externa, em relação ao núcleo, representam fontes de fluxos comunicacionais críticos que precisam passar pelo filtro do complexo institucional nuclear:

O centro constitui um sistema de comportas, a ser atravessado por muitos processos no âmbito do sistema político-jurídico, porém ele só pode controlar a regulação e a dinâmica desses processos até certo ponto. Modificações podem surgir, tanto na periferia, como no centro [...]. A ideia da democracia repousa, em última instância, no fato de que os processos políticos de formação da vontade, que no sistema aqui delineado têm um status periférico ou intermediário, devem ser decisivos para o desenvolvimento político. ${ }^{46}$

${ }_{44}$ Cf. PETERS, B. Die Integration moderner Gesellschaften. Frankfurt: Suhrkamp, 1993.

45 DD2, p. 86.

46 PETERS, 1993 apud DD2, p. 88. 
As decisões impositivas resultantes da passagem pelos canais estreitos do núcleo, "[...] para serem legítimas, têm que ser orientadas por fluxos comunicacionais que partem da periferia e atravessam as comportas dos procedimentos próprios à democracia e ao Estado de direito antes de passar pela porta de entrada do complexo parlamentar ou dos tribunais". ${ }^{47}$ Com isso se garantem as ligações necessárias (de "controle" mútuo) entre o poder comunicativo parlamentar e os poderes administrativo e social. Garante-se, assim, presença ao poder comunicativo em todas as instâncias da estrutura da sociedade.

Por um lado, devem-se preservar as forças anárquicas das liberdades comunicativas, mas, por outro, terão que passar por procedimentos democráticos e estabelecidos pelo Estado de direito, para que se efetivem pelo médium do direito. Tanto essa contracorrente de fluxos comunicacionais quanto padrões estabelecidos para as operações no núcleo do sistema político contribuem para a redução da complexidade do ciclo oficial da comunicação, desburocratizando os processos decisórios. Também aqui deve ficar garantida a presença de impulsos renovadores oriundos da periferia. O padrão faz parte de qualquer processo de formação de vontade política e de outros processos de normatização e implementação, porém o desafio consiste em conservar a porosidade desses padrões, para haver um equilíbrio entre processos formais e informais dos fluxos comunicacionais.

Fica evidente a preocupação com um modo de operacionalidade que vive de "[...] uma consciência de crise, maior atenção pública, busca intensificada de soluções, tudo confluindo numa problematização". ${ }^{48}$ Quando problemas enfocados envolvem aspectos normativos, a opinião pública força a reelaboração dos problemas, para estas entrarem no âmbito das competências do Estado de direito. Tal pressão pública tem que ser permanente para que a sensibilidade, quanto à percepção dos problemas e a sua regulação jurídica, não entre, ela mesma, em crise e se transforme em passividade e inércia social.

A substituição das liberdades comunicativas por formas domesticadas de relações intersubjetivas e interinstitucionais ou intersistêmicos coloca em perigo não apenas a relação equilibrada entre os três poderes constitutivos do Estado de direito, mas também provoca um fechamento do sistema político como um todo, alienando-o das fontes comunicacionais e legitimadoras das esferas públicas e, mais especificamente, da esfera pública política, entendida como uma estrutura comunicacional enraizada no mundo da vida por meio da sociedade civil.

47 DD2, p. 88.

48 DD2, p. 89. 
Nos momentos de crise, gerados pelo conflito entre o "padrão estabelecido" e as forças problematizadoras, "[...] os parlamentos e tribunais, aos quais se reserva formalmente um tratamento construtivo e reconstrutivo das razões normativas, podem determinar faticamente a direção do fluxo da comunicação". ${ }^{49}$ Nesses momentos decisivos, há um retorno às fontes normativas do Estado democrático de direito: o parlamento e os tribunais terão que reconstruir racionalmente o caminho percorrido até o momento do conflito e possibilitar um reinício do processo normal e legítimo da formação democrática da opinião e da vontade, isto é, emancipar, de novo, o poder comunicativo gerado de forma democrática.

A responsabilidade pelo controle do poder social e administrativo deve operar nos limites legais e não se afastar das suas fontes públicas de legitimação. A periferia deve ser "[...] a) capaz de e b) ter razões para farejar problemas latentes de integração social (cuja elaboração é essencialmente política), identificá-los, tematizá-los e introduzi-los no sistema político, passando pelas comportas do complexo parlamentar (ou tribunais), fazendo com que o modo rotineiro seja quebrado". ${ }^{50}$

As estruturas comunicacionais periféricas, responsáveis pela formação de opiniões e vontades críticas e contestadoras, assumem, com isso, uma tarefa de suma importância para a regulação dos processos comunicativos, mas, para tanto, necessitam de dinâmicas internas espontâneas e independentes de redes de comunicação institucionalizadas. São necessárias esferas públicas, autônomas e capazes de ressonância, o que requer delas um contato permanente com associações da sociedade civil, introdução em padrões liberais da socialização e da cultura política. As esferas públicas dependem de um mundo da vida racionalizado. Há, porém, um limite para a espontaneidade social que não poder ser produzido e reproduzido nem multiplicado segundo vontades e necessidades conjunturais.

Os contextos do mundo da vida representam um limite para os parceiros jurídicos organizarem autonomamente a sua vida em comum. Apesar disso, assim parece, a astúcia de alguma razão superior não determina tal processo nem gera sentido em termos de espontaneidade social. A esfera pública se garante pela institucionalização jurídica via Estado de direito e se produz e se reproduz, permanentemente, por meio da articulação das forças periféricas, que se entendem como portadores de discursos problematizadores de normas e regras, de poderes, de competências e de fluxos comunicacionais reconhecidos 49 DD2, p. 90.

50 DD2, p. 90. 
oficial e juridicamente instituídos e, muitas vezes, expressos por poderes sociais que procuram privatizar e tornar intransparente aquilo que é e deve permanecer um bem público, partilhado de forma equitativa e caracterizado pela transparência.

\section{Considerações finais}

A leitura discursiva do direito e do Estado democrático de direito possibilita a Habermas mostrar a atuação da racionalidade comunicativa na multiplicidade dos discursos que articulam a totalidade das opiniões e vontades dos cidadãos. Por meio da sua institucionalização jurídica, efetiva-se no conjunto das atividades dos membros de uma comunidade, em especial, na vida de cidadãos autônomos, livres e atuantes tanto na esfera privada como pública. Essas forças novas de conexão atuam em todos os níveis da sociedade e não pertencem a um ou apenas alguns atores privilegiados. Trata-se de forças coercitivas fracas, mas extremamente eficazes, pois possibilitam e impulsionam uma vida em comunidade baseada na procura de um entendimento geradora de estruturas comunicacionais de reconhecimento e reciprocidade entre os participantes do projeto societal. ${ }^{51}$

Nessa perspectiva, reinterpreta-se o direito em função da constituição de uma comunidade de parceiros jurídicos que se entendem e se respeitam mutuamente como sujeitos livres e autônomos, portadores de direitos fundamentais e, ao mesmo tempo, destinatários desses direitos, portanto, responsáveis, moral e juridicamente, por uma convivência legítima em uma comunidade jurídica, sem que recorram à violência e se apoiem em fundamentos de ordem religiosa ou metafísica.

A razão que assumiu uma figura procedimental no processo da criação legítima do direito, o qual se move sob condições exigentes derivadas dos processos e pressupostos da comunicação, manifesta-se, nesta figura, repleto de idealizações e precisa ser relacionada com a política como um espaço no qual se desenvolvem processos de poder, interesses diversos se chocam e negociações ocupam grande parte das atividades dos participantes do jogo político.

O processo de formação política da opinião e da vontade torna-se uma nova exigência e não apenas confere legitimidade às instituições do Estado de direito, mas requer, para si mesmo, uma dinâmica procedimental de 51 É decisivo, para a compreensão adequada da constituição dessas comunidades comunicativas, reconhecer que "os que agem comunicativamente encontram-se numa situação que eles mesmos ajudam a constituir através de suas interpretações negociadas cooperativamente, distinguindo-se dos atores que visam o sucesso e que se observam mutuamente como algo que aparece no mundo objetivo" (DD2, p. 92-93, grifo nosso). 
atuação, para possibilitar a compreensão procedimental da democracia, articulada por uma política deliberativa e conservadora de uma normatividade que combina forças comunicacionais de entendimento com a força coercitiva de um direito que complementa, garante e protege o agir comunicativo nos sistemas capilares da sociedade, em sua totalidade.

\section{Referências}

ARAGÃO, Lúcia. Habermas: filósofo e sociólogo do nosso tempo. Rio de Janeiro: Tempo Brasileiro, 2002.

HABERMAS, Jürgen. Pensamento Pós-metafísico: estudos filosóficos. Rio de Janeiro: Tempo Brasileiro, 1990. 1996.

Legitimationsprobleme im Spätkapitalismus. Frankfurt am Main: Suhrkamp,

Direito e democracia: entre facticidade e validade. Trad. de Flávio B. Siebeneichler. Rio de Janeiro: Tempo Brasileiro, 1997. v. 1.

. Direito e democracia: entre facticidade e validade. Trad. de Beno Siebeneichler. Rio de Janeiro: Tempo Brasileiro, 1997. v. 2

. Direito e moral. Lisboa: Instituto Piaget, 1999.

. A constelação pós-nacional: ensaios políticos. Trad. Marcio Seligmann-Silva. São Paulo: Littera Mundo, 2001.

. A inclusão do outro: estudos de teoria política. Trad. George Sperber e Paulo Astor Soethe. São Paulo: Loyola, 2002.

KOLLER, Peter. Rationales Entscheiden und moralisches Handeln. In: NIDA-RÜMELIN, Julian. (Hrsg.), WESSELS, Ulla. Praktische Rationalität: Grundlagenprobleme und ethische Anwendung des rational choice-Paradigmas. Berlin, New York: de Gryter, 1993. Cap. IX, p. 281-311. (Perspektiven der analytischen Philosophie, Bd. 2).

MACPHERSON, C. B. A democracia liberal: origens e evolução. Rio de Janeiro: Zahar, 1978.

OLIVEIRA, Nythamar Fernandes de. Tractatus ethico-politicus: genealogia do ethos moderno. Porto Alegre: Edipucrs, 1999.

PETERS, Bernhard. Die Integration moderner Gesellschaften. Frankfurt: Suhrkamp, 1993.

REESE-SCHÄFER, Walter. Compreender Habermas. Trad. Vilmar Schneider. Petrópolis: Vozes, 2008.

WILKE, Helmut. Ironie des Staates. Frankfurt am Main: Suhrkamp, 1992. 